\title{
Role Of Dietary Antioxidants In Periodontitis: A Preventive Approach
}

\author{
Dr Neha Bansal ${ }^{1}$, MDS,Dr N. D. Gupta ${ }^{2}$, MDS \\ ${ }^{I}$ Dept. of Periodontics \& Community Dentistry,Dr Z. A. Dental College, A.M.U., Aligarh, india \\ ${ }^{2}$ Dept. Of Periodontics \& Community Dentistry,Dr Z. A. Dental College, A.M.U., Aligarh, india
}

\begin{abstract}
In periodontitis, one of the major pathologic patterns is an increased production of reactive oxygen species (ROS). Reactive oxygen species are produced by polymorph nuclear cells as an inflammatory response to invading pathogenic bacteria. This imbalance among the production of free radicals and local antioxidants results in periodontal tissue destruction and a state of oxidative stress develops. In recent years, beneficial effects of antioxidants against various chronic disorder induced by oxidative stress have received much attention. This review is intended to summarize the role of dietary antioxidants in prevention of periodontal disease.
\end{abstract}

Keywords: antioxidant, oxidative stress, periodontitis, ROS,

\section{Introduction}

Oxidative stress is a state of altered equilibrium when antioxidant system of body fails to regulate the levels of free radicals produced in the body. ${ }^{1}$ At low concentration, free radicals are involved in various cell functions as cell signaling but at high concentrations, they react with cell molecules especially protein, DNA and lipid molecules and mediate tissue damage. ${ }^{2}$ Excessive production of free radicals are involved in pathogenesis of various chronic inflammatory disorders including periodontal disease. ${ }^{3}$

Periodontal disease is a chronic inflammatory disorder that leads to tissue damage as a result of complex interactions between pathogenic bacteria and the host immune system. ${ }^{4-5}$ Patients with periodontal disease display increased PMN number and activity, resulting in high degree of ROS release, culminating in heightened oxidative stress in gingival tissue, periodontal ligaments, and alveolar bone. ${ }^{6}$ Recent reports have also suggested that ROS are produced by osteoclast at the ruffled border interface and may play a role in resorption? ${ }^{7}$.

Cells require adequate levels of Antioxidants in order to prevent tissue damage caused by excessive production of reactive oxygen species (ROS). This has been shown that additional intake of high grade antioxidants can reduce periodontal pocket depths as much as 3 times compared to scaling and root planning alone. ${ }^{8}$ Due to possible health benefits of antioxidants against periodontitis, increased intake of such nutrients have been recommended. The aim of this article is to provide an overview of the effects of antioxidant nutrients in periodontal health and disease.

\section{Antioxidant Micronutrients:}

Natural antioxidants are molecules that prevent cell damage against free radicals and are critical for maintaining optimum health in humans. ${ }^{9}$ Major sources of antioxidants in the human diet include cereals, fruits, vegetables, chocolate, oils and beverages such as tea, coffee, wine and fruit juices etc. Dietary antioxidants which possess strong antioxidant activities include vitamin $\mathrm{C}$ (ascorbate), vitamin $\mathrm{E}$, beta-carotene and the polyphenols. ${ }^{\mathbf{1 0}}$ Now days, among the recommendations for the maintenance of healthy periodontal tissues, focus is given on the value diet and nutritional supplementation also.

\subsection{Vitamin C:}

The importance of ascorbic acid, better known as vitamin $\mathrm{C}$, for periodontal health has long been known. The most appropriate sources of vitamin $\mathrm{C}$ are natural fruits such as kiwi fruit, citrous fruits, pepper etc. Green kiwi fruit is a rich source of vitamin $\mathrm{C}$ and it contains $93 \mathrm{mg}$ vitamin $\mathrm{C} / 100 \mathrm{~g}$ fruit whereas e.g. oranges contain vitamin $\mathrm{C}$ up to $53 \mathrm{mg} / 100$ g fruit. $^{11}$

Vitamin $\mathrm{C}$ is a most powerful antioxidant radical scavenger within the aqueous phase. ${ }^{12}$ It is a co-factor for lysyl and prolyl hydroxylase, involved in stabilization of the collagen triple helix. ${ }^{13}$ it act as acts as regenerator for other antioxidants in body such as vitamin E. ${ }^{14}$ Different PDL respond differently to ascorbic acid. Bone-forming PDL cells may differentiate further in the presence of ascorbic acid. ${ }^{15}$ In contrast, ascorbic acid may cause fibroblastic PDL cells to increase both collagen and collagenase-1 expression, maintaining a high state of matrix turnover. ${ }^{16}$ 
Due to high intracellular ascorbic acid concentrations in leukocytes especially PMN and macrophages (approx 10-40 times), these cells are capable to react in response to inflammatory stimuli. ${ }^{17}$ It not only enhances chemotaxis of normal PMNLs but also correct abnormal chemotaxis and lysosome degranulation in PMN from patients with Chediak-Higashi syndrome. ${ }^{18}$

Leggott et al. ${ }^{19}$ studied the effect of a nutrient rich diet but lacking vitamin $\mathrm{C}$, on periodontal health. The results suggested that ascorbic acid may influence early stages of gingivitis, particularly increased crevicular bleeding. However, in subsequent studies, no significant changes in plaque accumulation, probing pocket depth, or attachment level were noted. ${ }^{20}$ Blignaut \& Grobler showed that deeper pockets (CPITN code 3 and 4) occurred far less frequently in citrus fruit-producing farm workers than that of workers in grainproducing farms. ${ }^{21}$ Based on NHANES III survey, Nishida et al. ${ }^{22}$ revealed that the dietary vitamin $\mathrm{C}$ have a weak, but statistically significant inverse relationship to periodontal disease in current and former smokers. Using the same NHANES III data set Chapple et al. found a strong and consistent inverse association between serum vitamin $\mathrm{C}$ levels and the prevalence of periodontitis. ${ }^{23}$

Vitamin $\mathrm{C}$ can be well tolerated at doses well above the RDA recommendations, but high doses of vitamin $\mathrm{C}$ may generate toxicity due to the formation of vitamin $\mathrm{C}$ radicals. For many years the recommended daily intake of vitamin C was $60 \mathrm{mg}$. In 2000 Recommended Dietary Allowance (RDA) of vitamin C was increased by the Food and Nutrition Board from 60 to $90 \mathrm{mg}$ daily for men to $75 \mathrm{mg}$ daily for women. ${ }^{24}$

\subsection{Vitamin E :}

$\alpha$-tocopherol is the most active biological form of vitamin E. It is a fat soluble antioxidant, found most abundantly in nuts, seeds and vegetable oil as wheat germ oil, sunflower, and safflower oils. ${ }^{25}$ Vitamin $\mathrm{E}$ transfers phenolic hydrogen to the recipient free radical and gets converted into phenoxyl radical. However, this phenoxyl radical is no longer an antioxidant and it must be recycled or repaired. ${ }^{26}$ Water-soluble vitamin $\mathrm{C}$ is the popular candidate for this role but thiols and particularly GSH can also function in this role in vitro. Vitamin E can help to control periodontal disease through its ability to prevent inflammation. Taking vitamin E might helps diabetics, control their blood glucose levels thereby it might help reduce the side effects of the disease including the development of periodontal disease.

Studies on vitamin E showed Mixed Results. Sobaniec found that there are significantly low levels of vitamin $\mathrm{E}$ and other antioxidants in saliva of epilepsy patients with periodontal disease. ${ }^{27}$ Cohen RE et al compared the use of a 5\% vitamin $\mathrm{E}$ gel, a chlorhexidine rinse and a placebo on plaque and periodontal disease ${ }^{28}$. After two weeks, participants using the placebo and the vitamin E gel showed no improvement in the amount of plaque or gum inflammation but chlorhexidine significantly reduced plaque. In another study no significant difference in the levels of serum vitamin $\mathrm{E}$ in patients with and without periodontal disease was found. ${ }^{29}$ Although it has been suggested that vitamin E might be beneficial in the prevention of periodontal disease, but its overall effect on periodontal health is not fully understood. Data do not provide sufficient support for the treatment of inflammatory periodontal disease with vitamin $\mathrm{E}$ and more researches are needed in this area.

\subsection{Carotenoids:}

Carotenoid antioxidants (alpha carotene, beta-carotene, crytoxanthin, lutein, lycopene, zeanxantin) are a group of natural colored pigments, usually yellow, red or orange, that are widespread in plants. ${ }^{30}$ They act as free radical traps. They have protective effects on vitamin $\mathrm{C}$ and $\mathrm{E}$ and have synergistic effects by scavenging reactive nitrogen species. ${ }^{31} \beta$-carotene is the main source of provitamin $\mathrm{A}$ in the diet. Due to the fact that carotenoid levels have influence on other antioxidant molecules therefore they are regarded as cardinal in antioxidant defense system. Svilaas et al revealed that carotenoids are predictors of all in all antioxidant status. ${ }^{32}$

Carotenoids are powerful antioxidants. They may also be involved in regulating cell-to-cell communication or gene expression. Carotenoid rich diet is correlated with a diminished risk various degenerative disorders including cancer, cardiovascular or ophthalmological diseases. ${ }^{33}$

Linden et al. evaluated the correlation between periodontal health and serum levels multiple antioxidants. ${ }^{34} \mathrm{He}$ noticed that levels of $\alpha$ and $\beta$ carotene, $\beta$ cryptoxanthin, and zeaxanthin were significantly lower in moderate and severe periodontitis patients however no such association was found in the levels of lutein, lycopene, $\alpha$ tocopherol or retinol with periodontitis. Walston et al found that patients with low levels of $\alpha$ - and $\beta$-carotene and total carotenoids were more likely to have high interleukin-6.5

$\beta$-Cryptoxanthin has an anabolic effect on bone metabolism. It has been shown to stimulates bone formation and inhibit bone resorption. ${ }^{36}$ Also it inhibits gene expression of osteoclastic enzymes which are involved in bone resorption. It is suggested that increased intake of fruit and vegetables containing $\beta$ cryptoxanthin could reduce the risk of osteoporosis. ${ }^{37}$ Therefore $\beta$-Cryptoxanthin could be relevant to periodontal destruction, given its potential osteogenic activity on bone rather than through its activity as an antioxidant. 


\subsection{Flavonoids :}

Flavonoids are polyphenolic compounds found in fruits, vegetables and certain beverages. Dietary intake of flavonoids is quite high compared to other dietary antioxidants. They have antioxidant, antiinflammatory, anti-allergic, antiplatelet and antitumor activities. ${ }^{38}$ It also has an inhibitory action on bacterial collagenase. Synergistic relationship between flavonoids and vitamin $\mathrm{C}$ has also been established. ${ }^{39}$ Highflavonoid foods help to protect blood vessels from rupture or leakage, protect cells from oxygen damage, and prevent excessive inflammation throughout body. ${ }^{40}$ Green tea has flavonoid components called catechin that may reach 1 gram per cup. Other rich sources of flavonoids are Cocoa, berry, onion, apple etc.

Tomofuji et al showed that rats feasted on a cocoa enriched diet could develop experimental periodontitis, however the serum ROS levels and the GSH ratio was shown to be maintained in gingival tissues. ${ }^{41}$ Sonia N. revealed that there is significant reduction of the gingival bleeding index in the green tea consumers group as well as in the group of patients that followed the flavonoid treatment. ${ }^{42}$ Kushiyama et al. demonstrated that the intake of green tea was inversely related with mean pocket depth, bleeding on probing and clinical attachment level. ${ }^{43}$ Balbin showed that green tea can completely inhibit the activity of collagenase in GCF in aggressive periodontitis patients. ${ }^{44}$ It was demonstrated that flavonoids may restore the alveolar therefore provide a bone mass by inhibiting LPS-induced bone resorption. ${ }^{45,46}$ Therefore increased intake of flavonoids may proved to be beneficial prevention of periodontal disease.

\section{Conclusion:}

Specific foods and combinations of various micronutrients can improve the response to therapies. Also nutritional counseling and supplementation reduces inflammation and hence can complement treatment concepts. Due to the potential health benefits, antioxidant nutrients have opened a new window for prevention and treatment of periodontal diseases and diet should be supplemented with natural antioxidants. However to correctly evaluate the relationship of dietary antioxidants and periodontal health, further controlled clinical studies are needed.

\section{Reference:}

[1]. Halliwell B, Gutteridge JM. Role of free radicals and catalytic metal ions in human disease: An overview. Methods Enzymol 1990; 186: $1-85$

[2]. Poli G, Leonarduzzi G, Biasi F, et al. Oxidative stress and cell signaling. Curr Med Chem 2004; 11: 1163-82

[3]. Chapple IL, Matthews JB. The role of reactive oxygen and antioxidant species in periodontal tissue destruction. Periodontol 2000. 2007; 43: 160-232.

[4]. Lee M-I, Shoji H, Yoshino F. The role of free radicals on oral inflammatory disease. Presented at IADR/AADR/CADR 82nd General Session: March 10-13, 2004, Honolulu, Hawaii. Abstract 2444.

[5]. Ritchie, Christine et al. Nutrition, inflammation, and periodontal disease. Nutrition and Oral Health, 2003; $19: 475-476$.

[6]. Chapple ILC. Role of free radicals and antioxidants in the pathogenesis of inflammatory periodontal diseases. Clinical Molecular Pathology 1996; 49: 247-255

[7]. Steinbeck MJ, Appel WH Jr, Verhoeven AJ. NADPH-oxidase expression and in situ production of superoxide by osteoclasts actively resorbing bone. J Cell Biol 1994 Aug; 126(3): 765-72.

[8]. Www.wellnessintegration.info/.../Dental\%20Studies.pdf

[9]. Halliwell B. How to characterize an antioxidant- An update. Biochem Soc Symp 1995; 61: 73-101

[10]. McCall MR, Frei B. Can antioxidant vitamins materially reduce oxidative damage in humans? Free Rad Biol Med 1999; 26: 103453

[11]. USDA National Nutrition Database for Standard Reference, release 22 (2010) Available at http:// www.ars.usda.gov/SP2UserFiles/Place/12354500/ Data/SR22/nutrlist/sr22a401.pdf

[12]. Wilson, J. X. Regulation of vitamin C transport. Annual Review of Nutrition 2005; 25: 105-25.

[13]. Robertson, W. V. The biochemical role of ascorbic acid in connective tissue. Annals of the New York Academy of Sciences 1961; 92: $159-167$

[14]. Niki, E., Noguchi, N., Tsuchihashi, H., Gotoh, N. Interaction among vitamin C, vitamin E, and beta-carotene. Am. J. Clin. Nutr 1995; 62: 1322S-1326S.

[15]. Mimori, K., Komaki, M., Iwasaki, K. \& Ishikawa, I. Extracellular signal-regulated kinase $1 / 2$ is involved in ascorbic acid-induced osteoblastic differentiation in periodontal ligament cells. Journal of Periodontology 2007; 78: 328-34.

[16]. Shiga, M., Kapila, Y. L., Zhang et al. Ascorbic acid induces collagenase- 1 in human periodontal ligament cells but not in MC3T3E1 osteoblast-like cells: potential association between collagenase expression and changes in alkaline phosphatase phenotype. Journal of Bone and Mineral Research 2003; 18: 67-77.

[17]. Oberritter, H., Glatthaar, B., Moser, U. \& Schmidt, K. H. Effect of functional stimulation on ascorbate content in phagocytes under physiological and pathological conditions. International Archives of Allergy and Applied Immunology 1986; 81: 46-50.

[18]. Hughes, DA. Effects of dietary antioxidants on the immune function of middle-aged adults. The Proceedings of the Nutrition Society 1999 Feb; 58(1): 79-84

[19]. Leggott, P. J., Robertson, P. B., Rothman, D. L., Murray, P. A. \& Jacob, R. A. The effect of controlled ascorbic acid depletion and supplementation on periodontal health. Journal of Periodontology 1986; 57: 480-485.

[20]. Leggott, P. J., Robertson, P. B., Jacob, R. A., Zambon, J. J., Walsh, M. \& Armitage, G. C. Effects of ascorbic acid depletion and supplementation on periodontal health and subgingival microflora in humans $1991 \mathrm{Dec} ; 70(12): 1531-1536$

[21]. Blignaut, J. B. \& Grobler, S. R. High fruit consumption and the periodontal status of farm workers. Clinical Preventive Dentistry 1992; 14: 25-28.

[22]. Nishida, M., Grossi, S. G., Dunford, R. G., Ho, A. W., Trevisan, M. \& Genco, R. J. Dietary vitamin C and the risk for periodontal disease. Journal of Periodontology 2000; 71(8): 1215-1223. 
[23]. Chapple, I. L. C. \& Matthews, J. B. The role of reactive oxygen and antioxidant species in periodontal tissue destruction. Periodontology 2000. 2007; 43: 160-232.

[24]. Dietary Reference Intakes for Vitamin C, Vitamin E, Selenium, and Carotenoids. Washington, DC: National Academy Press, 2000.

[25]. Reboul E, Richelle M, Perrot E, Desmoulins-Malezet C, Pirisi V, Borel P. Bioaccessibility of carotenoids and vitamin E from their main dietary sources. Journal of Agricultural and Food Chemistry 2006 Nov; 54(23): 8749-8755

[26]. Book Vitamin and Mineral Requirements in Human Nutrition. World Health Organization, 2004.

[27]. Sobaniec et al. Antioxidant Activity Of Blood Serum And Saliva In Patients With Periodontal Disease Treated Due To Epilepsy. Advances in Medical Science. 2007; 52(1)

[28]. Cohen RE, Ciancio SG, Mather ML, Curro FA. Effect of vitamin E gel, placebo gel and chlorhexidine on periodontal disease. Clin Prev Dent 1991 Sep-Oct; 13(5): 20-4

[29]. Slade EW Jr, Bartuska D, Rose LF, Cohen DW. Vitamin E and periodontal disease. J Periodontol 1976 Jun; $47(6)$ : $352-4$.

[30]. Higdon J: Carotenoids. In An Evidence-Based Approach to Dietary Phytochemicals 2006: 47-61

[31]. Boohm, F., Edge, R., McGarvey, D.J., Truscott, T.G. Beta-carotene with vitamins E and C offers synergistic cell protection against NOx. FEBS Lett 1998a; 436: 387-389

[32]. Svilaas A, Salhl AK, Anderson AF, Svilaas T et al. Intakes of Antioxidants in Coffee, Wine and Vegetables are Correlated with Plasma Carotenoids in Humans. J Nutr 2004; 134: 562-7

[33]. Mayne, S.T. Beta-carotene, carotenoids, and disease prevention in humans. FASEB J 1996; 10: 690-701

[34]. Linden GJ, McClean KM, Woodside JV, Patterson CC, Evans A, Young IS, et al. Antioxidants and periodontitis in 60-70-year-old men. J Clin Periodontol 2009; 36: 843-9

[35]. Walston, J., Xue, Q., Semba, R. D., Ferrucci, L. ea al. Serum antioxidants, inflammation, and total mortality in older women. American Journal of Epidemiology 2006; 163: 18-26.

[36]. Yamaguchi M, et al. Role of carotenoid $\beta$-cryptoxanthin in bone homeostasis. Mol Cell Biochem 2004 Mar; 258 (1-2): 137-44.

[37]. Sugiura M, Nakamura M, Ogawa K, Ikoma Y, Ando F, Yano M. Bone mineral density in post-menopausal female subjects is associated with serum antioxidant carotenoids. Osteoporosis Int. 2008; 19: 211-219

[38]. Joe A Vinson, Jinhee Jang. In vitro and in vivo lipoprotein antioxidant effect of a citrus extract and ascorbic acid on normal and hypercholesterolemic human subject. Journal Of Medicinal Food 2001 Nov; 4

[39]. AR Tapas, DM Sakarkar1, and RB Kakde. Flavonoids as Nutraceuticals: A Review. Tropical Journal of Pharmaceutical Research 2008 September; 7(3): 1089-1099

[40]. http://whfoods.org/genpage.php?tname=nutrient\&dbid=119

[41]. Tomofuji T., Ekunial D. et al. Preventive effects of a ocoaenriched diet on gingival oxidative stress in experimental periodontitis. Journal of Periodontology Nov 2009; 80: 1799-1808.

[42]. Sonia N., Silvia M. et al. Dual effects of flavonoids on dyslipidemia and Periodontal disease. Romanian Journal of Oral Rehabilitation Dec 2011; 3(4)

[43]. Kushiyama, M., Shimazaki, Y., Murakami, M. \& Yamashita, Y. Relationship between intake of green tea and periodontal disease. Journal of Periodontology 2009; 80: 372-377.

[44]. Balbin M, Fueyo A, Tester AM et al. Loss of collagenase-2 confers increased skin tumour susceptibility to male mice. Nat Genet 2003; 35: 252-257

[45]. Yue Chen et al. Influence of Baicalin on Alveolar Bone Resorption in Rat Experimental Periodontitis. scipharm 2008; 76: 689-698

[46]. Tsukasa Tominari1, Michiko Hirata. Polymethoxy Flavonoids, Nobiletin and Tangeretin, Prevent Lipopolysaccharide-Induced Inflammatory Bone Loss in an Experimental Model for Periodontitis. Journal of Pharmacological Sciences 2012; 119: 390-394 